\title{
iTRAQ-Based Quantitative Proteomic Analysis of Digestive Juice across the First 48 Hours of the Fifth Instar in Silkworm Larvae
}

\author{
Pingzhen $\mathrm{Xu}{ }^{1,2, \dagger}$, Meirong Zhang ${ }^{1,2, \dagger}$, Ping Qian ${ }^{1,2}$, Jiawei $\mathrm{Li}^{1}{ }^{1}$, Xueyang Wang ${ }^{1,2}$ and \\ Yangchun $\mathrm{Wu}^{1,2, *}$ \\ 1 School of Biotechnology, Jiangsu University of Science and Technology, Sibaidu Rd, Zhenjiang 212018, China; \\ xpz198249@just.edu.cn (P.X.); zhangmr@just.edu.cn (M.Z.); qianping@just.edu.cn (P.Q.); \\ 162212001131@just.edu.cn (J.L.); xueyangwang@just.edu.cn (X.W.) \\ 2 Sericulture Research Institute, Chinese Academy of Agricultural Sciences, Sibaidu Rd, \\ Zhenjiang 212018, China \\ * Correspondence: 199400001939@just.edu.cn; Tel.: +86-551-8561-6539; Fax: +86-551-8563-9848 \\ + These authors contributed equally to this work.
}

Received: 4 November 2019; Accepted: 3 December 2019; Published: 4 December 2019

\begin{abstract}
The silkworm is an oligophagous insect for which mulberry leaves are the sole diet. The nutrients needed for vital activities of the egg, pupal, and adult stages, and the proteins formed in the cocoon, are all derived from the larval stages. The silkworm feeds and grows quickly during the larval stages. In particular, the amount of leaf ingested and digested quickly increases from the ecdysis to the gluttonous stage in the fifth instar period. In this study, we used the iTRAQ proteomic technique to identify and analyze silkworm larval digestive juice proteins during this period. A total of 227 proteins were successfully identified. These were primarily serine protease activity, esterase activity, binding, and serine protease inhibitors, which were mainly involved in the digestion and overcoming the detrimental effects of mulberry leaves. Moreover, 30 genes of the identified proteins were expressed specifically in the midgut. Temporal proteomic analysis of digestive juice revealed developmental dynamic features related to molecular mechanisms of the principal functions of digesting, resisting pathogens, and overruling the inhibitory effects of mulberry leaves protease inhibitors (PIs) with a dynamic strategy, although overruling the inhibitory effects has not yet been confirmed by previous study. These findings will help address the potential functions of digestive juice in silkworm larvae.
\end{abstract}

Keywords: Bombyx mori; iTRAQ; proteomics; digestive juice

\section{Introduction}

The silkworm, Bombyx mori, is a complete metamorphosis insect. It is not only a domestic insect of economic significance, but also a model insect of Lepidoptera, which is widely used in basic and applied research [1,2]. The silkworm is an oligophagous insect and mulberry leaves are its sole diet [3]. The silkworm digestive system is a simple tube that runs longitudinally along the central body cavity from the mouth to the anus in larval stages. The digestive tube can be divided into the foregut, midgut, and hindgut according to its function and structure [4]. The main functions of the foregut are physical digestion, consisting of feeding, grinding, swallowing, and temporary storage of mulberry leaves. The hindgut is present in the midgut transition that is generally thought to reabsorb certain salts and amino acids from food residue to maintain water balance and/or osmotic pressure in the silkworm [5-7]. The midgut is the most important section and comprises approximately 78 percent of the total length of the digestive tube. The midgut originates from the endoderm that consists of muscle, basilar membrane, epithelium 
layer, and peritrophic envelope [8]. The main functions of the midgut are chemical digestion focused on digesting and absorbing with the action of enzymes in digestive juice.

Digestive juice is secreted by cylindrical and cup cells in the midgut. Cylindrical cells are the main components of epithelial cells and cup cells are mainly distributed in the interior of epithelial cells [9]. The silkworm digestive juice has an alkaline $\mathrm{pH}$ between 9.2 and 9.8, and the highly alkaline $\mathrm{pH}$ between 10.5 and 11.0 in the central midgut region. The gut $\mathrm{pH}$ is one of the most important regulators of digestive enzyme activity in insects [10]. The macromolecular nutrients must be degraded into small molecules by digestive enzymes before they can be absorbed by epithelial cells. There are many kinds of digestive enzymes with high activities in the midgut of silkworm. According to the location of these digestive enzymes, they can be divided into two categories. The first is exoenzymes that are synthesized by epithelial cells and involved in the degradation of macromolecular nutrients, such as trypsin, lipase, amylase, and nuclease. These enzymes can work efficiently under alkaline conditions. The other type is endoenzymes, which are mainly located in the microvilli of cylindrical cells. The most suitable $\mathrm{pH}$ value is almost neutral or faintly acidic, such as peptidase and oligosaccharide enzymes. The silkworm is oligophagous and consumes a significant quantity of fresh mulberry leaves, which have a high growth rate. Comparative proteomics analyses between mulberry leaves and silkworm feces indicate that large amounts of proteins from mulberry leaves are absorbed and digested by silkworm larvae [11]. The silkworm larval midgut has a complex proteolytic environment with different properties. Examining the enzyme activities in digestive juice, the amylase has a positive correlation with survivability, and the alkaline phosphatase and invertase has positive roles in the expression of yield attributes [12-14]. The esterases, specific $\beta$-esterase bands (Est-1, 2 and 3 ), have been documented as being present in digestive juice [14]. Catalyzing food protein hydrolysis is a crucial step in digestion. Serine proteases (SPs) that catalyze the hydrolysis of peptide bonds in proteins are the most abundant proteinase in digestion $[15,16]$. It has been confirmed that the digestive enzymes are all responsible for protein digestion, including trypsins, chymotrypsins, elastases, cathepsin B-like proteases, aminopeptidases, and carboxypeptidases [16].

Bacteria and viruses, excluding fungi, can infect B. mori larvae via the oral pathway. As larvae ingest the occlusion-derived virus (ODV) of nucleopolyhedrovirus (NPV), the alkaline digestive juice dissolves it and releases the enveloped virions, which then begin to infect the midgut columnar epithelial cells [16]. The roles of many proteins in digestive juice to resist pathogens have been investigated in silkworms. The novel red fluorescent protein (RFP) purified from silkworm digestive juice possesses antiviral, antifungal, and antibacterial properties [17]. Multiple forms of RFPs (A, B and C) exhibit unique specificity in neutralizing the different viruses, namely NPV, cypovirus (CPV), infectious flacherie virus (IFV), and densovirus (DNV) to different degrees [18]. RFP was detected only in the digestive juice and was not detected in the hemolymph [17]. Light is essential in the synthesis of RFPs in B. mori-fed mulberry leaves. RFPs have been reported to inactivate NPV and the molecular weights of each are significantly different [18-20]. Different varieties of silkworms have varying numbers of RFPs that are related to the susceptibilities of the silkworms to viral disease [21]. Serine proteases (SPs) and serine protease homologs (SPHs) showing strong antiviral activity in the digestive juice of silkworm have been previously reported [16,22,23].

The amount of leaf ingested and digested increases daily from the first to the third days of the fifth instar silkworm larva (before the gluttonous stage). In this period, the risk of silkworm infection is potentially raised. Therefore, the silkworm may need higher digestive enzyme activity and more active immune activity. However, the previous studies investigating the digestive juice proteins have not been conducted at the whole proteomics level. Moreover, the components of digestive juice proteins have not been analyzed in different developmental periods. In the present study, we used the iTRAQ quantitative proteomic technique to identify and analyze silkworm digestive juice proteins in different developmental periods. This work first focused on the complex composition of silkworm digestive juice, in order to understand the complex biological processes in nutrient digestion that are very important before the silkworm larvae progresses to the gluttonous stage. 


\section{Results}

\subsection{Protein Profiling}

After processing all MS/MS spectra in Mascot software, 1126 unique tryptic peptides were mapped to 227 proteins from silkworm digestive juice. The unique tryptic peptides defining each protein and 227 successfully identified proteins are shown in Table S1, including the information of each protein relating to the locus name of a gene in the silkworm genome, each protein accession number from the NCBInr database, the probe number from the silkworm microarray database, the predicted signal peptide, the functional description, the identified percentage of total amino acid sequence, and the number of unique peptides per protein. A total of 182 of the 227 identified proteins had signal peptides. The 227 proteins were identified in digestive juice from ecdysis to gluttonous stages in the fifth instar period. The amount of leaf ingested and digested by silkworm larvae most quickly increases in this period, such that it may need higher digestive enzyme activity and more immune activity in digestive juice. Remarkably, among the 227 identified proteins, there were 20 serine proteases, 21 serine protease inhibitors, 9 carboxypeptidases, 9 aminopeptidases, 7 lipases, 6 lipoproteins, 4 collagenases, 6 immune-related proteins, 12 enzymes involved in nucleic acid metabolism, 10 enzymes involved in sugar metabolism, and 22 uncharacterized proteins (Table S1). In addition, the isoelectric points of 70 proteins were between 7.01 and 11.94 (Table S1).

\subsection{Identification of Differentially Expressed Proteins}

The threshold for up- and downregulation of a fold change of $\geq 2.0$ or $\leq 0.5$ was found to be differentially expressed in digestive juice of the three developmental stages in comparison with each other. In DJ24h (feeding $24 \mathrm{~h}$, day two of fifth instar) compared with DJ0h (feeding $0 \mathrm{~h}$, day one of fifth instar), 43 proteins were upregulated and 28 proteins were downregulated (Figure 1A and Table 1, Table S2). In DJ48h (feeding $48 \mathrm{~h}$, day three of fifth instar) compared with DJ0h, 63 proteins were upregulated and 50 proteins were downregulated (Figure 1A and Table 1, Table S2). Thus, it can be seen that the number of differentially expressed proteins (DEPs) increases with the feeding time. A total of 27 proteins were upregulated and 40 proteins were downregulated in DJ48h compared with DJ24h (Figure 1A and Table 1, Table S2). In total, there were 11 DEPs across the comparison of the three groups (Figure 1B). The functions of upregulated expression proteins were mainly focused on protein and carbohydrate metabolism, and serine protease activity in DJ24h compared with DJ0h; serine protease activity and protein and carbohydrate metabolism in DJ48h compared with DJ0h; and protein and carbohydrate metabolism in DJ48h compared with DJ24h (Table 1, Table S2). Moreover, the functions of downregulated expression proteins were primarily located in the binding proteins of ions, fatty acids, and chitin in DJ24h compared with DJ0h; serine protease inhibitor and binding proteins of ions, fatty acids, and chitin in DJ48h compared with DJ0h; and serine protease inhibitor and serine protease activity in DJ48h compared with DJ24h (Table 1, Table S2).
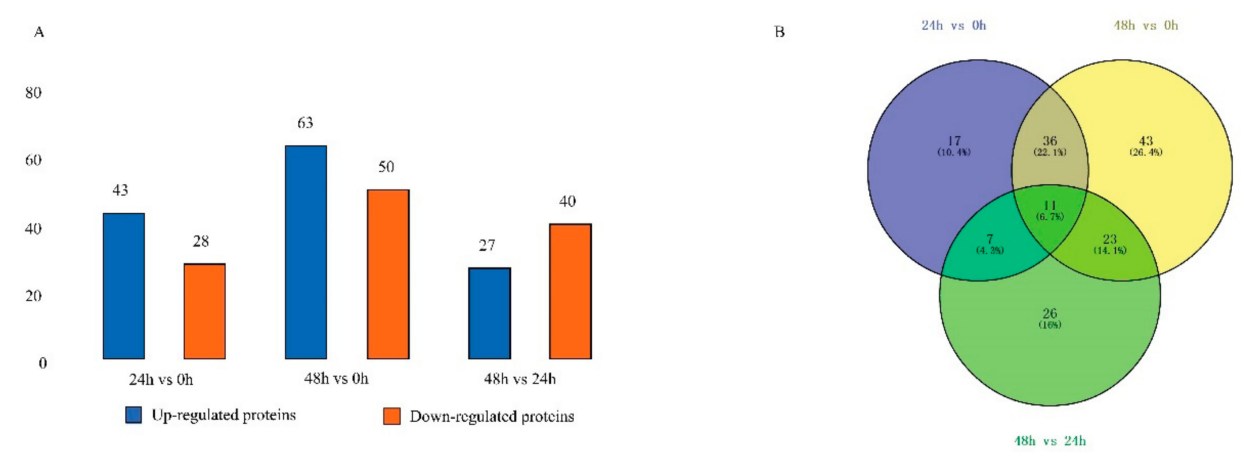

Figure 1. Identification and analysis of the differentially expressed proteins (DEPs) in digestive juice of the three developmental stages. (A) Up- and downregulated DEPs in digestive juice in the three stages. (B) DEP distribution Venn diagram. 
Table 1. List of the proteins upregulated in silkworm digestive juice at $24 \mathrm{~h}$ and $48 \mathrm{~h}$ growth stages.

\begin{tabular}{|c|c|c|c|c|c|}
\hline Time (h) & Number & Accession & SilkDB Accession & Fold Change & Function \\
\hline \multirow[t]{35}{*}{$\mathrm{DJ} 24 / 0 \mathrm{~h}$} & 1 & H9J8I4 & BGIBMGA005826 & 2.11 & Alcohol dehydrogenase activity \\
\hline & 2 & H9IW77 & BGIBMGA001508 & 2.19 & Carboxylic ester hydrolase activity \\
\hline & 3 & Q58I81 & - & 4.18 & Ester bonds hydrolase activity \\
\hline & 4 & Н9JТК9 & BGIBMGA012871 & 2.02 & Ester bonds hydrolase activity \\
\hline & 5 & H9ISX5 & BGIBMGA000353 & 3.24 & Innate immune \\
\hline & 6 & Q86D78 & BGIBMGA003512 & 2.72 & Beta-glucosidase \\
\hline & 7 & H9JCF2 & BGIBMGA007153 & 2.73 & Glycosyl hydrolase activity \\
\hline & 8 & H9JL39 & BGIBMGA010240 & 3.96 & Chitinase activity \\
\hline & 9 & H9JSN7 & BGIBMGA012548 & 3.21 & Sphingomyelin phosphodiesterase activity \\
\hline & 10 & B1Q138 & - & 2.37 & Carboxylesterase activity \\
\hline & 11 & H9JTY2 & BGIBMGA012994 & 3.01 & CN_hydrolase activity \\
\hline & 12 & B1Q137 & - & 3.08 & Carboxylesterase activity \\
\hline & 13 & H9IWD7 & BGIBMGA001568 & 2.57 & Maltase-glucoamylase activity \\
\hline & 14 & $\mathrm{~B} 2 \mathrm{ZZX0}$ & BGIBMGA008818 & 4.87 & Phosphatase activity \\
\hline & 15 & H9JT78 & BGIBMGA012740 & 2.82 & Peroxidase activity \\
\hline & 16 & H9JBZ7 & BGIBMGA007042 & 2.92 & Peroxidase activity \\
\hline & 17 & P10831 & - & 3.33 & Peptidase regulator \\
\hline & 18 & Q03383 & - & 2.02 & Antichymotrypsin \\
\hline & 19 & C0J8G5 & BGIBMGA003292 & 3.63 & Serine protease inhibitor \\
\hline & 20 & H9IXK0 & BGIBMGA001983 & 10.24 & Serine protease inhibitor \\
\hline & 21 & Н9JH30 & BGIBMGA008827 & 13.22 & Serine protease inhibitor \\
\hline & 22 & I3VR74 & BGIBMGA008061 & 2.53 & AMP deaminase activity \\
\hline & 23 & B5TZ28 & BGIBMGA007915 & 4.92 & Metallopeptidase activity \\
\hline & 24 & H9J232 & BGIBMGA003569 & 2.96 & Serine protease activity \\
\hline & 25 & H9J267 & BGIBMGA003604 & 3.19 & Serine protease activity \\
\hline & 26 & H9JL75 & BGIBMGA010276 & 3.15 & Serine protease activity \\
\hline & 27 & H9JJ 25 & BGIBMGA009526 & 4.40 & Serine protease activity \\
\hline & 28 & H9JJ26 & BGIBMGA009527 & 3.72 & Serine protease activity \\
\hline & 29 & H9IWJ8 & BGIBMGA001630 & 2.32 & Cholinesterase activity \\
\hline & 30 & H9JDE9 & BGIBMGA007546 & 2.19 & Carboxylesterase activity \\
\hline & 31 & H9J067 & BGIBMGA002902 & 2.84 & Cholinesterase activity \\
\hline & 32 & H9IWK8 & BGIBMGA001640 & 2.89 & Aminopeptidase activity \\
\hline & 33 & H9JJ19 & BGIBMGA009520 & 6.95 & WD repeat domain phosphoinositide-interacting \\
\hline & 34 & Q1HPY8 & - & 4.25 & Guanine nucleotide binding \\
\hline & 35 & H9J1D5 & BGIBMGA003322 & 2.28 & Juvenile hormone binding \\
\hline
\end{tabular}


Table 1. Cont.

\begin{tabular}{|c|c|c|c|c|c|}
\hline Time (h) & Number & Accession & SilkDB Accession & Fold Change & Function \\
\hline \multirow{34}{*}{ DJ48/0 h } & 36 & H9JK60 & BGIBMGA009911 & 2.05 & Ubiquitin-activating \\
\hline & 37 & H9IVY4 & BGIBMGA001415 & 2.08 & Ubiquitin-mediated protein binding \\
\hline & 38 & $\mathrm{C} 1 \mathrm{~K} 001$ & BGIBMGA004287 & 5.34 & N/A \\
\hline & 39 & H9JN76 & BGIBMGA010979 & 2.20 & $\mathrm{~N} / \mathrm{A}$ \\
\hline & 40 & H9J1D8 & BGIBMGA003325 & 3.80 & $\mathrm{~N} / \mathrm{A}$ \\
\hline & 41 & H9JXD9 & BGIBMGA014204 & 2.36 & $\mathrm{~N} / \mathrm{A}$ \\
\hline & 42 & H9JPZ3 & BGIBMGA011598 & 2.39 & $\mathrm{~N} / \mathrm{A}$ \\
\hline & 43 & H9J1D9 & BGIBMGA003326 & 2.33 & $\mathrm{~N} / \mathrm{A}$ \\
\hline & 1 & H9IW76 & BGIBMGA001507 & 5.27 & Lipase \\
\hline & 2 & C7EPE2 & BGIBMGA000158 & 5.42 & $\begin{array}{c}\text { Glucose-methanol-choline (GMC) oxidoreductase } \\
\text { activity }\end{array}$ \\
\hline & 3 & H9JFH1 & BGIBMGA008268 & 3.06 & Aldehyde oxidase activity \\
\hline & 4 & H9J8I4 & BGIBMGA005826 & 3.90 & Alcohol dehydrogenase activity \\
\hline & 5 & H9JTY7 & BGIBMGA012999 & 2.94 & Glucose dehydrogenase activity \\
\hline & 6 & H9ISL2 & BGIBMGA000239 & 3.87 & Peroxidase activity \\
\hline & 7 & H9ISL1 & BGIBMGA000238 & 7.03 & Peroxidase activity \\
\hline & 8 & H9JT78 & BGIBMGA012740 & 3.46 & Peroxidase activity \\
\hline & 9 & H9IX93 & BGIBMGA001876 & 2.78 & Alpha-amylase activity \\
\hline & 10 & Q86D78 & BGIBMGA003512 & 3.44 & Beta-glucosidase \\
\hline & 11 & B2DD57 & BGIBMGA005696 & 2.81 & Glycosyl hydrolase activity \\
\hline & 12 & H9JCF2 & BGIBMGA007153 & 3.18 & Glycosyl hydrolase activity \\
\hline & 13 & A0A077JI83 & BGIBMGA006066 & 3.90 & O-Glycosyl hydrolase activity \\
\hline & 14 & H9ISX5 & BGIBMGA000353 & 8.99 & Innate immune \\
\hline & 15 & H9JPS6 & BGIBMGA011531 & 2.85 & Phospholipase C activity \\
\hline & 16 & H9IVS0 & BGIBMGA001351 & 3.11 & Oxidoreductase activity \\
\hline & 17 & $\mathrm{~B} 2 \mathrm{ZZX0}$ & BGIBMGA008818 & 2.74 & Phosphatase activity \\
\hline & 18 & Q9NGS0 & - & 3.05 & N/A \\
\hline & 19 & P81902 & - & 3.16 & Trypsin inhibitor \\
\hline & 20 & Q03383 & - & 3.14 & Antichymotrypsin \\
\hline & 21 & C0J8G5 & BGIBMGA003292 & 7.33 & Serine protease inhibitor \\
\hline & 22 & C0J8H1 & - & 12.35 & $\mathrm{~N} / \mathrm{A}$ \\
\hline & 23 & C4B489 & BGIBMGA004445 & 2.19 & Serine protease activity \\
\hline & 24 & H9JFI3 & BGIBMGA008280 & 3.17 & Serine protease activity \\
\hline & 25 & H9J229 & BGIBMGA003566 & 2.04 & Serine protease activity \\
\hline & 26 & Н9JKH3 & BGIBMGA010024 & 2.37 & Serine protease activity \\
\hline
\end{tabular}


Table 1. Cont

\begin{tabular}{|c|c|c|c|c|c|}
\hline Time (h) & Number & Accession & SilkDB Accession & Fold Change & Function \\
\hline & 27 & H9JG67 & BGIBMGA008514 & 2.02 & Serine protease activity \\
\hline & 28 & H9JY09 & BGIBMGA014427 & 2.44 & Serine protease activity \\
\hline & 29 & H9J231 & BGIBMGA003568 & 2.72 & Serine protease activity \\
\hline & 30 & H9JJ26 & BGIBMGA009527 & 2.64 & Serine protease activity \\
\hline & 31 & H9JIY5 & BGIBMGA009486 & 2.33 & Carboxypeptidase activity \\
\hline & 32 & H9JESO & BGIBMGA008017 & 2.37 & AMP deaminase activity \\
\hline & 33 & H9JEW2 & BGIBMGA008059 & 4.47 & Aminopeptidase activity \\
\hline & 34 & H9JDE9 & BGIBMGA007546 & 3.86 & Carboxylesterase activity \\
\hline & 35 & H9JE19 & BGIBMGA007766 & 2.35 & Phosphoric diester hydrolase activity \\
\hline & 36 & B5TZ28 & BGIBMGA007915 & 3.13 & Metallopeptidase activity \\
\hline & 37 & H9IWJ8 & BGIBMGA001630 & 2.01 & Cholinesterase activity \\
\hline & 38 & H9JSJ8 & BGIBMGA012509 & 3.51 & Glucosinolate sulphatase activity \\
\hline & 39 & H9J064 & BGIBMGA002899 & 2.18 & Carboxylesterase activity \\
\hline & 40 & H9J067 & BGIBMGA002902 & 3.26 & Cholinesterase activity \\
\hline & 41 & B2ZDZ0 & BGIBMGA009544 & 2.04 & Carboxylesterase activity \\
\hline & 42 & CoSQ80 & BGIBMGA008354 & 2.00 & Odorant binding \\
\hline & 43 & A1YQ87 & BGIBMGA005493 & 3.08 & Phosphopyruvate hydratase activity \\
\hline & 44 & H9JP12 & BGIBMGA011266 & 3.08 & Insect hexamerins \\
\hline & 45 & H9J128 & BGIBMGA003215 & 4.77 & RNA binding \\
\hline & 46 & H9JLC5 & BGIBMGA010326 & 3.09 & Mitochondrial carriers \\
\hline & 47 & H9IVY4 & BGIBMGA001415 & 3.89 & Ubiquitin-mediated protein binding \\
\hline & 48 & H9IT95 & BGIBMGA000475 & 5.80 & Cation binding \\
\hline & 49 & Q69FX2 & BGIBMGA008221 & 2.34 & Innate immunity and lipid metabolism \\
\hline & 50 & S5M110 & BGIBMGA005577 & 2.25 & Carbohydrate derivative binding \\
\hline & 51 & $\mathrm{C} 1 \mathrm{~K} 001$ & BGIBMGA004287 & 3.16 & N/A \\
\hline & 52 & H9JYG4 & BGIBMGA009648 & 5.55 & DNA binding \\
\hline & 53 & H9IYN2 & BGIBMGA002366 & 2.16 & N/A \\
\hline & 54 & Q2F645 & BGIBMGA014211 & 2.03 & Transketolase activity \\
\hline & 55 & H9J1D5 & BGIBMGA003322 & 4.40 & Juvenile hormone binding \\
\hline & 56 & H9J5L9 & BGIBMGA004809 & 3.95 & Lyase activity \\
\hline & 57 & H9J1D8 & BGIBMGA003325 & 4.85 & N/A \\
\hline & 58 & H9JT75 & BGIBMGA012737 & 2.58 & Peroxidase activity \\
\hline & 59 & H9JXD9 & BGIBMGA014204 & 2.02 & N/A \\
\hline & 60 & H9JPZ3 & BGIBMGA011598 & 3.59 & N/A \\
\hline & 61 & Н9Ј3М9 & BGIBMGA004116 & 2.02 & Transferase activity \\
\hline & 62 & H9J1D9 & BGIBMGA003326 & 8.57 & N/A \\
\hline & 63 & H9JXN1 & BGIBMGA014298 & 12.23 & $\mathrm{~N} / \mathrm{A}$ \\
\hline
\end{tabular}


Table 1. Cont.

\begin{tabular}{|c|c|c|c|c|c|}
\hline Time (h) & Number & Accession & SilkDB Accession & Fold Change & Function \\
\hline \multirow{28}{*}{ DJ48/24 h } & & & & & \\
\hline & 1 & H9IW76 & BGIBMGA001507 & 2.87 & Lipase \\
\hline & 2 & C7EPE2 & BGIBMGA000158 & 4.05 & $\begin{array}{c}\text { Glucose-methanol-choline (GMC) oxidoreductase } \\
\text { activity }\end{array}$ \\
\hline & 3 & H9JFH1 & BGIBMGA008268 & 2.12 & Aldehyde oxidase activity \\
\hline & 4 & H9ISL2 & BGIBMGA000239 & 2.30 & Peroxidase activity \\
\hline & 5 & H9ISL1 & BGIBMGA000238 & 4.67 & Peroxidase activity \\
\hline & 6 & H9IX93 & BGIBMGA001876 & 2.52 & Alpha-amylase activity \\
\hline & 7 & B2DD57 & BGIBMGA005696 & 2.01 & Glycosyl hydrolase activity \\
\hline & 8 & A0A077JI83 & BGIBMGA006066 & 3.67 & O-Glycosyl hydrolase activity \\
\hline & 9 & A1YQ87 & BGIBMGA005493 & 3.06 & Phosphopyruvate hydratase activity \\
\hline & 10 & P81902 & - & 2.03 & Trypsin inhibitor \\
\hline & 11 & C0J8H1 & - & 2.02 & N/A \\
\hline & 12 & H9JKL1 & BGIBMGA010062 & 3.09 & Serine-type endopeptidase activity \\
\hline & 13 & H9J5K7 & BGIBMGA004797 & 2.14 & Metallocarboxypeptidase activity \\
\hline & 14 & H9JG67 & BGIBMGA008514 & 2.28 & Serine protease activity \\
\hline & 15 & H9J5P0 & BGIBMGA004830 & 2.12 & Metallocarboxypeptidase activity \\
\hline & 16 & H9JIY5 & BGIBMGA009486 & 2.41 & Carboxypeptidase activity \\
\hline & 17 & H9JG68 & BGIBMGA008515 & 4.20 & Serine protease activity \\
\hline & 18 & H9JHZ0 & BGIBMGA009138 & 2.00 & Aminopeptidase activity \\
\hline & 19 & A7LIK7 & BGIBMGA004403 & 2.14 & $30 \mathrm{~K}$ protein \\
\hline & 20 & H9J128 & BGIBMGA003215 & 2.72 & RNA binding \\
\hline & 21 & H9JLC5 & BGIBMGA010326 & 3.06 & Mitochondrial carriers \\
\hline & 22 & H9IVY4 & BGIBMGA001415 & 2.24 & Ubiquitin-mediated protein binding \\
\hline & 23 & H9JUE4 & BGIBMGA013157 & 3.54 & Ribosomal protein \\
\hline & 24 & Q8N0P2 & BGIBMGA002381 & 3.43 & 70 kilodalton heat shock protein \\
\hline & 25 & H9J5L9 & BGIBMGA004809 & 2.80 & Lyase activity \\
\hline & 26 & H9J1D9 & BGIBMGA003326 & 3.69 & N/A \\
\hline & 27 & H9JXN1 & BGIBMGA014298 & 6.68 & N/A \\
\hline
\end{tabular}

"-" indicates that no SilkDB accession BGI number was found. N/A: not applicable. 
A total of nine carboxypeptidases were successfully identified in silkworm digestive juice; among them, BGIBMGA004830, BGIBMGA009486 and BGIBMGA004797 were upregulated in DJ48/24h (Table 1, Table S1). Meanwhile, nine aminopeptidases were also successfully identified; BGIBMGA008061 and BGIBMGA001640 were upregulated in DJ24/0h, BGIBMGA008017 and BGIBMGA008059 were upregulated in DJ48/0h, and BGIBMGA009138 was upregulated in DJ48/24h (Table 1, Table S1). Moreover, five serine proteases associated with immune response during Escherichia coli and Bacillus bombyseptieus infection were identified (Table 1, Figure S1); BGIBMGA003604 and BGIBMGA010276 were upregulated in DJ24/0h, BGIBMGA003568, BGIBMGA003566 and BGIBMGA008514 were upregulated in DJ48/0h. The abundance of innate immune pattern-recognition receptor beta-1,3-glucan recognition protein 4 (BGIBMGA000353) was increased daily from day one to day three of the fifth instar larvae in digestive juice (Table 1 ). These results suggest that the digestion and immunity of $B$. mori larvae are gradually enhanced.

\subsection{Gene Ontology and Kyoto Encyclopedia of Genes and Genomes Pathway Enrichment Analysis of DEPs}

After obtaining the differentially expressed proteins (DEPs), they were annotated by Gene Ontology (GO) analysis to be involved in biological processes, molecular functions, and cellular components (Figure 2). The DEPs identified in DJ24h compared with DJOh were significantly enriched for proteins related to biological processes that were basically focused on metabolic processes and cellular processes (Figure 2A, Table S3). With regard to the molecular function, proteins were involved in catalytic activity and binding (Figure 2A, Table S3). Within the cellular component, the DEPs were primarily located in the extracellular region (Figure 2A, Table S3). In DJ48h compared with DJ24h, regarding biological processes, the DEPs were mainly focused on metabolic processes, single-organism processes, and cellular processes; for the molecular function, proteins were involved in catalytic activity and binding; and within the cellular component, proteins were primarily located in the extracellular region (Figure 2B, Table S4). There were some differences in the GO functional annotation of the differentially expressed proteins from the two comparison groups (Figure 2). Kyoto Encyclopedia of Genes and Genomes (KEGG) pathway enrichment analysis of the identified DEPs showed that the enriched proteins were mainly involved in pathways, including galactose metabolism, sphingolipid metabolism, folate biosynthesis, ubiquitin mediated proteolysis, and purine metabolism in DJ24h compared with DJOh, and their functions were related to metabolisms, development, regulation of innate immune signaling, and antiviral properties (Table 2, Table S5). Meanwhile, in DJ48h compared with DJ24h, the enriched proteins were mainly involved in pathways, including folate biosynthesis, lysosome, galactose metabolism, fructose and mannose metabolism, pentose and glucuronate interconversions, purine metabolism, and peroxisome (Table 3, Table S6).
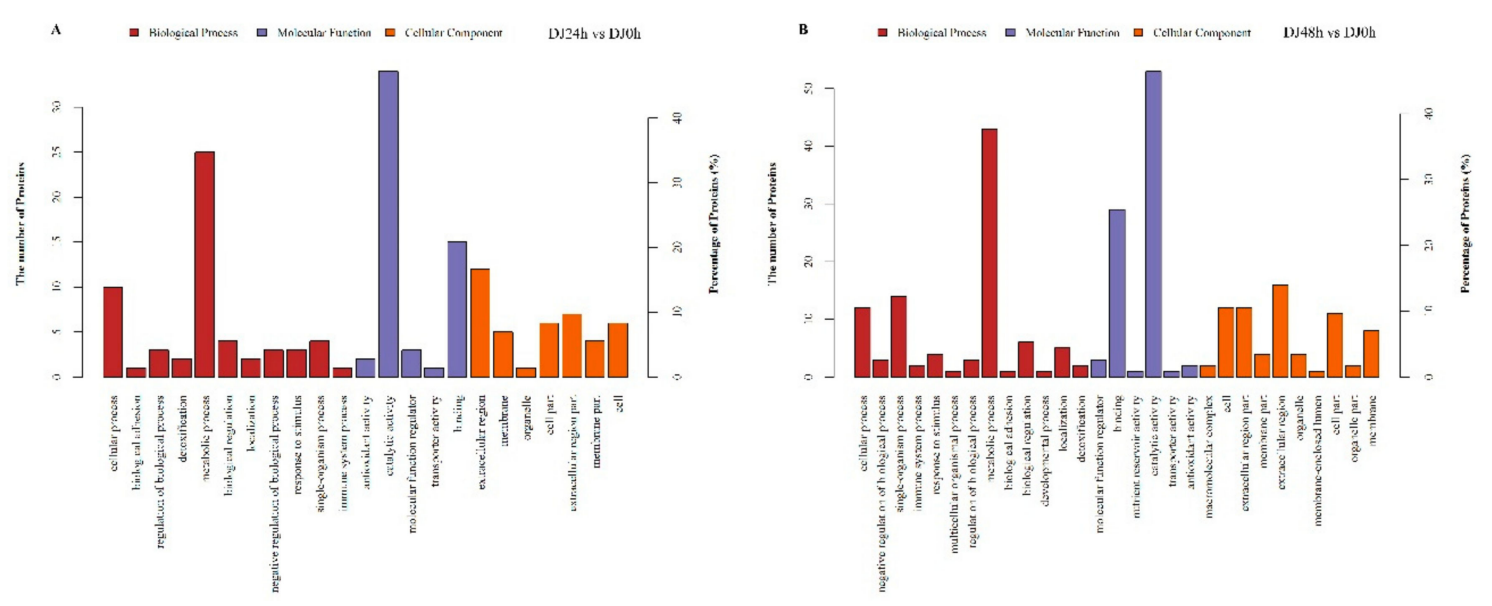

Figure 2. Gene ontology enrichment analysis for DEPs. Proteins are annotated by biological process, cellular component, and molecular function. (A) The group of DJ24h (feeding $24 \mathrm{~h}$ ) compared with DJ0h (feeding $0 \mathrm{~h}$ ). (B) The group of DJ48h (feeding $48 \mathrm{~h}$ ) compared with DJ24h (feeding $24 \mathrm{~h}$ ). 
Table 2. Top 10 of the KEGG pathway enrichment analysis of DEPs in DJ24h compared with DJ0h.

\begin{tabular}{ccccc}
\hline Number & Map_Name & Map_ID & Protein_ID & Definition \\
\hline 1 & Galactose metabolism & map00480 & F8V3L0 & gamma-glutamyltranspeptidase [24] \\
2 & Lysosome & map04142 & H9JSN7 & sphingomyelin phosphodiesterase [25] \\
3 & Sphingolipid metabolism & map00600 & H9JSN7 & sphingomyelin phosphodiesterase [26] \\
4 & Arachidonic acid metabolism & map00590 & F8V3L0 & gamma-glutamyltranspeptidase [24] \\
5 & Taurine and hypotaurine metabolism & map00430 & F8V3L0 & gamma-glutamyltranspeptidase [24] \\
6 & Neuroactive ligand-receptor interaction & map04080 & H9JL75 & trypsin [27] \\
7 & Folate biosynthesis & map00790 & B2ZZX0 & alkaline phosphatase [28] \\
8 & Thiamine metabolism & map00730 & B2ZZX0 & alkaline phosphatase [28] \\
9 & Ubiquitin mediated proteolysis & map04120 & H9JK60 & ubiquitin-activating enzyme E1 [29] \\
10 & Caffeine metabolism & map00232 & H9JFX4 & xanthine dehydrogenase/oxidase [30] \\
\hline
\end{tabular}


Table 3. Top 10 of the KEGG pathway enrichment analysis of DEPs in DJ48h compared with DJ24h.

\begin{tabular}{|c|c|c|c|c|c|}
\hline Number & Map_Name & Map_ID & Protein_ID & Definition & Fold Change \\
\hline \multirow[t]{4}{*}{1} & Folate biosynthesis & map00790 & H9IVS0 & aldehyde reductase [31] & 3.11 \\
\hline & & & $\mathrm{B} 2 \mathrm{ZZX} 0$ & alkaline phosphatase [28] & 4.18 \\
\hline & & & H9JTG9 & aldehyde reductase [32] & 0.50 \\
\hline & & & H9IVT6 & aldehyde reductase & 0.06 \\
\hline \multirow[t]{3}{*}{2} & Lysosome & map04142 & Q69FX2 & niemann-Pick C2 protein $[33,34]$ & 2.34 \\
\hline & & & A4PHN6 & hexosaminidase [35] & 0.50 \\
\hline & & & H9IWR3 & lysosomal alpha-mannosidase [36] & 0.47 \\
\hline \multirow[t]{3}{*}{3} & Galactose metabolism & map00052 & H9IVSO & aldehyde reductase [37] & 3.11 \\
\hline & & & H9JTG9 & aldehyde reductase [32] & 0.50 \\
\hline & & & H9IVT6 & aldehyde reductase & 0.06 \\
\hline \multirow[t]{3}{*}{4} & Fructose and mannose metabolism & map00051 & H9IVSO & aldehyde reductase [37] & 3.11 \\
\hline & & & H9JTG9 & aldehyde reductase [32] & 0.50 \\
\hline & & & H9IVT6 & aldehyde reductase & 0.06 \\
\hline \multirow[t]{3}{*}{5} & Pentose and glucuronate interconversions & map00040 & H9IVSO & aldehyde reductase [37] & 3.11 \\
\hline & & & H9JTG9 & aldehyde reductase [32] & 0.50 \\
\hline & & & H9IVT6 & aldehyde reductase & 0.06 \\
\hline \multirow[t]{3}{*}{6} & Glycerolipid metabolism & map00561 & H9IVSO & aldehyde reductase [37] & 3.11 \\
\hline & & & H9JTG9 & aldehyde reductase [32] & 0.50 \\
\hline & & & H9IVT6 & aldehyde reductase & 0.06 \\
\hline \multirow[t]{3}{*}{7} & Purine metabolism & map00230 & H9JFH1 & xanthine dehydrogenase/oxidase [30] & 3.06 \\
\hline & & & H9JDV4 & nucleoside-diphosphate kinase [38] & 0.26 \\
\hline & & & H9JFX4 & xanthine dehydrogenase/oxidase [30] & 0.38 \\
\hline \multirow[t]{3}{*}{8} & Peroxisome & map04146 & H9JFH1 & xanthine dehydrogenase/oxidase [30] & 3.06 \\
\hline & & & $\mathrm{Q} 08 \mathrm{~J} 22$ & superoxide dismutase, $\mathrm{Cu}-\mathrm{Zn}$ family $[39,40]$ & 0.33 \\
\hline & & & H9JFX4 & xanthine dehydrogenase/oxidase [30] & 0.38 \\
\hline \multirow[t]{2}{*}{9} & Starch and sucrose metabolism & map00500 & H9IX93 & alpha-amylase [41] & 2.78 \\
\hline & & & H9J822 & alpha-trehalase [42] & 0.42 \\
\hline \multirow[t]{2}{*}{10} & Glutathione metabolism & map00480 & H9JESO & aminopeptidase N [43] & 2.37 \\
\hline & & & H9JEW2 & aminopeptidase N [43] & 4.47 \\
\hline
\end{tabular}




\subsection{Protein-Protein Interaction Network Analysis of DEPs}

For further analysis, DEPs were submitted to the STRING database to generate protein-protein interaction networks. The main results of the enrichment network indicated that Ubi3 comprised the central node of protein-protein interactions (Figure 3). Swiss-Prot accession number H9IVY4 was consistent with BGIBMGA001415, which encoded polyubiquitin-A protein (Ubi3) with the full length of 913 aa. The Ubi3 contained twelve ubiquitin (UBQ) domains predicted by SMART online. Its GO function was protein binding (GO:0005515). Ubiquitin is mainly fused with ribosomal proteins [44,45]. Multiple ribosomal proteins interacting with Ubi3 were found in the STRING database (Figure S2). However, there were H9JYG4 (BGIBMGA009648, histone H), H9JK60 (BGIBMGA009911, ubiquitin-activating enzyme E1), O97158 (BGIBMGA011424, transferrin), and Q86D78 (BGIBMGA003512, beta-glucosidase) interacting with Ubi3 among all the DEPs in digestive juice, respectively (Figure 3). These results suggest that Ubi3 may be involved in the digestion process of the developmental periods.

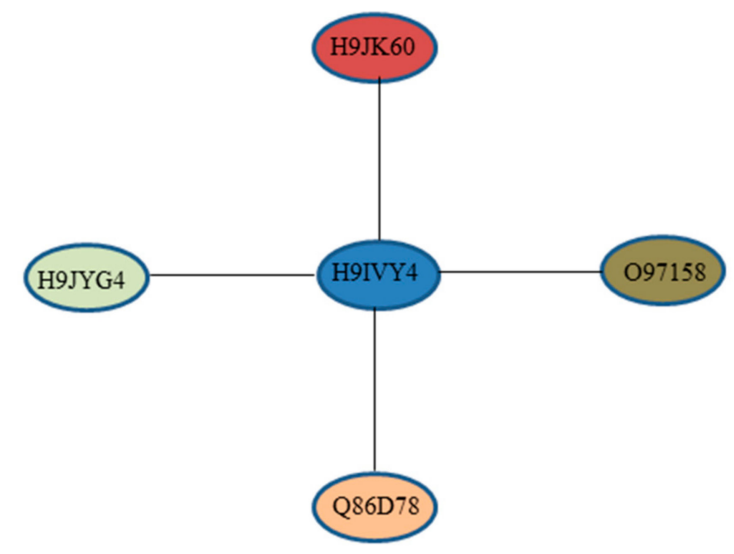

Figure 3. Protein-protein interaction networks of DEPs. Prediction and analysis of protein-protein interaction networks of all the DEPs was supported by STRING. H9IVY4: BGIBMGA001415, polyubiquitin-A, protein binding (GO:0005515). H9JYG4: BGIBMGA009648, histone H3, DNA binding (GO:0003677). H9JK60: BGIBMGA009911, ubiquitin-activating enzyme E1, protein binding (GO:0005515). O97158: BGIBMGA011424, transferrin, iron ion binding (GO:0005506). Q86D78: BGIBMGA003512, glucosidase, hydrolase activity (GO:0016787).

\subsection{Spatial Expression Profile of Genes of the Identified Proteins}

Day three of the fifth instar of the silkworm is the boundary for whole larval development stage [2]. The fifth instar of silkworm larva feeds and grows quickly before this time, but afterward, the silkworm hemolymph proteins gradually change and silkworms to synthesize massively silk proteins in the silk gland $[2,46]$. In order to investigate the spatial expression profile of genes of the identified proteins in digestive juice, the microarray data were downloaded from SilkDB, including the gene expression level across 10 B. mori larval tissues of day three of the fifth instar [2]. Thus, the study of this point in time will be helpful to elucidate the synthesis and secretory mechanism of digestive juice proteins. Genes of the identified digestive juice proteins had expression signals in at least one tissue (Figure 4, Figure S3, Table S7). A total of 21 genes had expression signals in all 10 tissues (Figure S3, Table S7). Most of the genes had high expression features in the midgut. Thirty genes expressed specifically in the midgut (Figure 4A, Table S8). 57 genes expressed significant high in the midgut (Figure 4B, Table S9). The midgut-specific genes encoded enzymes, hydrolase, and binding proteins that were involved in the digestion of mulberry leaves by GO functional annotation. These diverse expression characteristics suggest that digestive juice proteins are mainly secreted by digestive tube and the majority of the enzymatic digestion largely takes place in the midgut. 
A

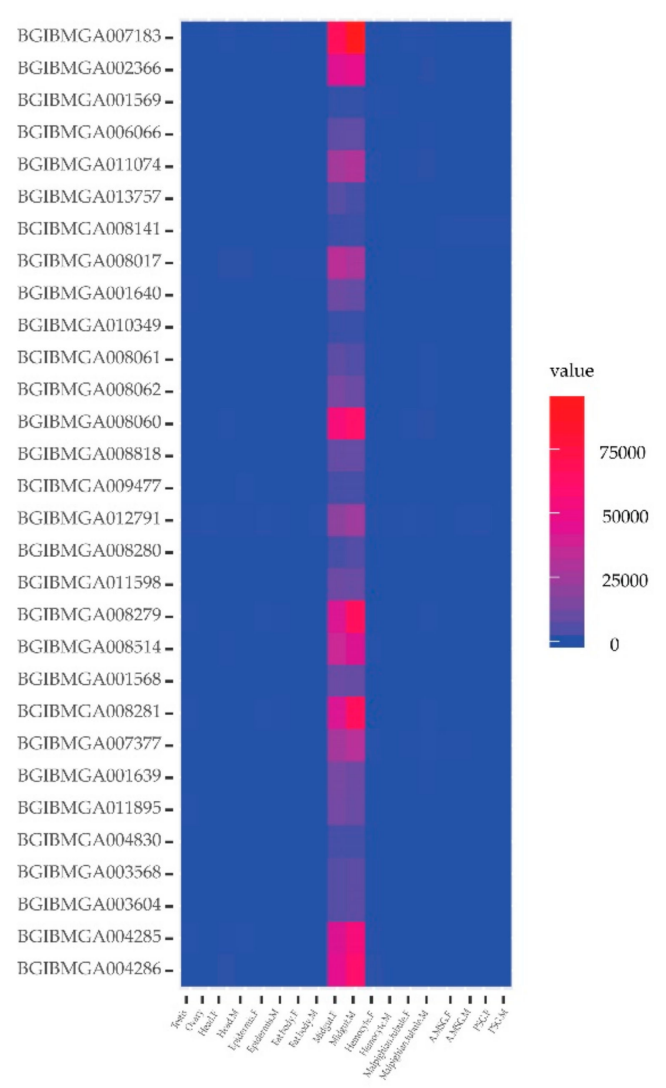

B

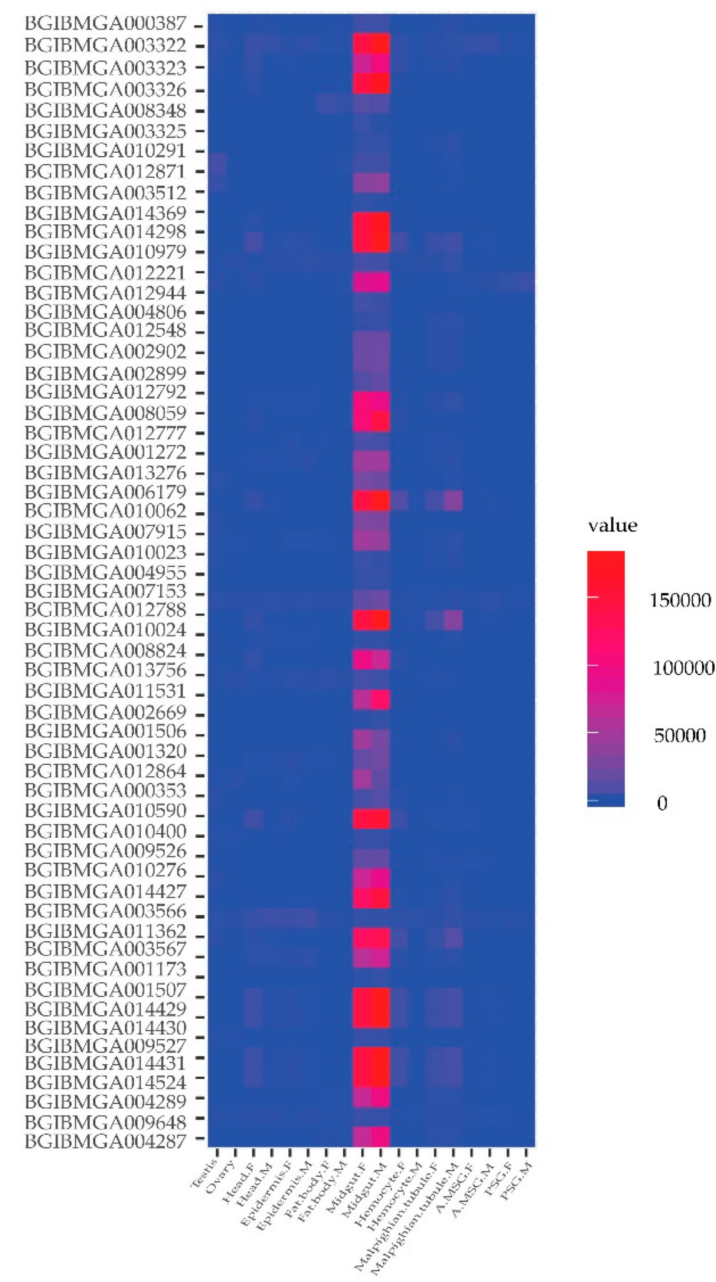

Figure 4. Tissue expression profile of genes of the identified digestive juice proteins in larvae on day three of the silkworm fifth instar. (A) The genes expressed specifically in the midgut. (B) The genes expressed significant high in the midgut. The columns represent ten different tissues with both sexes: testis, ovary, head, epidermis, fat body, midgut, hemocyte, Malpighian tubule, anterior/median silk gland (A/MSG), posterior silk gland (PSG), female (F), and male (M). Gene expression levels are represented by red (higher expression) and blue (lower expression) boxes. The mean value of the microarray data of each gene is calculated in each tissue.

\subsection{Expression Analysis of Genes Corresponding to DEPS}

In the previous section, the genes of the identified digestive juice proteins were mainly expressed in the midgut. Thus, we used midgut tissue to verify whether the changes in protein level were consistent with the transcriptional level and also to examine the proteomics data. The three time-points of midgut and digestive juice were identical. RT-qPCR was used to investigate expression levels of genes of the DEPs at the three time-points. The information of the selected differentially expressed genes and B. mori ribosomal protein gene BmRPL3 primers are presented in Table S10. The eight genes for encoding four up- and downregulated proteins were selected, respectively. The changes of the eight genes' transcription were generally consistent with their encoding proteins in the iTRAQ data (Figure 5). 

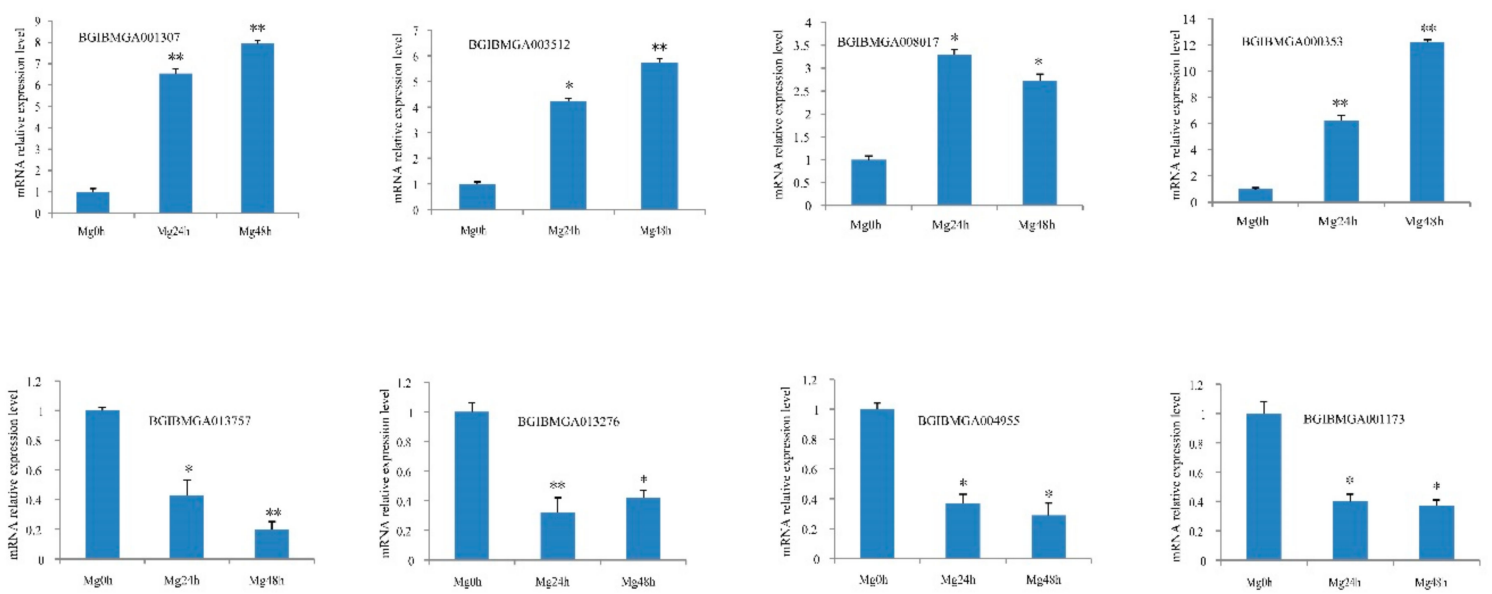

Figure 5. Analysis of changes in transcription level via RT-qPCR corresponding to the DEPs. For each gene, the mRNA level at $\mathrm{Mg} 0 \mathrm{~h}$ (midgut from day one of fifth instar larvae) is set as 1 . The experiments were repeated three times. B. mori ribosomal protein gene BmRPL3 is used as an internal control. The data are the means \pm SD of three independent experiments. The significant differences are indicated by $*(p<0.05)$ or ${ }^{* *}(p<0.01)$.

\section{Discussion}

Silkworm larvae grow rapidly and the weight of the terminal fifth instar larvae is approximately 10,000 times that of a newly hatched larvae. Only the larvae feed during the whole lifecycle. The nutrients needed for the vital activities of egg, pupal, and adult stages, and the proteins formed in the cocoon, are derived from the larval stage. The core value of the larval stage is feeding, absorption, and accumulation of nutrients. In particular, the amount of leaf ingested and digested quickly increases from immediately after ecdysis to the gluttonous stage in the fifth instar period. At the same time, the risk of oral infection is potentially raised. Therefore, the characteristics of the ingredients and variation of silkworm digestive juice proteins are of interest.

In this study, we used iTRAQ to analyze proteomes in silkworm digestive juice and 227 proteins were successfully identified. The classifications of the whole identified proteins were mainly serine protease activity, esterase activity, binding, and serine protease inhibitor, which were mainly involved in the digestion and overruling the detrimental effects of mulberry leaves. The spatial expression profiles of the genes of the identified digestive juice proteins showed that most of the genes had high expression features in the midgut and 30 genes expressed in the midgut displayed tissue-specificity. The silkworm feeds and grows quickly from day one to day three of the fifth instar [46]. The abundance of identified proteins in day one, two, and three of fifth silkworm instar digestive juice was compared. In DJ24h compared with DJ0h, 43 proteins were upregulated and 28 proteins were downregulated; in DJ48h compared with DJ0h, 63 proteins were upregulated and 50 proteins were downregulated; and 27 proteins were upregulated and 40 proteins were downregulated in DJ48h compared with DJ24h. These results indicate that the digestive juice comprises a dynamically changing protein mixture in the developmental periods. Day three of the fifth instar is the boundary for whole larval development; after this time, silkworm hemolymph proteins around $30 \mathrm{kDa}$ and $80 \mathrm{kDa}$ gradually increase, and silkworms to synthesize mass silk proteins in the silk gland $[2,47,48]$. Therefore, silkworms need to strongly increase their digestive efficiency.

The silkworm needs to acquire essential nutrients from mulberry leaves by digesting dietary proteins, carbohydrates and lipids. Proteins are digested into amino acids and oligopeptides by digestive enzymes [10]. Trypsins, chymotrypsins, elastases, cathepsin-B like proteases, aminopeptidases, and carboxypeptidases are all responsible for protein digestion in lepidopteran larvae $[15,16]$. The exopeptidases are further divided into carboxypeptidases (cleaving at the carboxylic terminus) and aminopeptidases (cleaving at the amino terminus). A total of 48 genes encoding carboxypeptidases 
have been identified in silkworm and 11 midgut-specific carboxypeptidases were significantly downregulated after starvation and restored after re-feeding [49]. A total of 9 carboxypeptidases were successfully identified in silkworm digestive juice; among them, BGIBMGA004830, BGIBMGA009486, and BGIBMGA004797 were upregulated in DJ48/24h. Meanwhile, nine aminopeptidases were also successfully identified; BGIBMGA008061 and BGIBMGA001640 were upregulated in DJ24/0h, BGIBMGA008017 and BGIBMGA008059 were upregulated in DJ48/0h, and BGIBMGA009138 was upregulated in DJ48/24h. Serine proteases include trypsins, chymotrypsins, and elastases, which are known to dominate the larval gut environment and contribute to the majority (as much as $95 \%$ ) of the total proteolytic activity in the gut of larval Lepidoptera $[10,15]$. The sources of mulberry leaf sugars are sucrose, starch, and reducing sugars, such as glucose and fructose [50]. Only monosaccharides of the end products of carbohydrate digestion are absorbed and utilized. The sugar absorbed and metabolized is essential for silkworm larval development and cocoon production [51]. The initial digestion of carbohydrates is mediated by amylases and only alpha-amylases have the activity to catalyze starch and glycogen in insects [10,52]. BGIBMGA001876 (silkworm alpha-amylase) was upregulated in DJ48/0h and DJ48/24h. Smaller polysaccharides and disaccharides produced by catalysis of $\alpha$-amylase are further degraded to monosaccharides during subsequent steps of carbohydrate digestion performed by distinct enzymes [10,53]. After the initial breakdown of large oligosaccharides by amylases, $\alpha$-glucosidase and $\beta$-fructofuranosidase mediate the subsequent degradation of oligo- and disaccharides into monosaccharides [10,51]. Sugar mimicking alkaloids, such as 1,4-dideoxy-1,4-imino-D-arabinitol (D-AB1) and 1-deoxynojirimycin (DNJ) derived from mulberry latex, are strong inhibitors of $\alpha$-glucosidase but do not exhibit inhibitory activity against $\beta$-fructofuranosidase ( $\beta$-FFase) [54,55]. BGIBMGA005696 (BmSuc1) was upregulated in DJ48/0h and DJ48/24h that is a novel animal $\beta$-FFase cloned and identified in B. mori $[51,56]$. BmSuc1 acts as an essential sucrase by directly modulating the degree of sucrose hydrolysis and silencing BmSuc1, significantly reducing glucose in the midgut and leading to smaller body size, lighter weight, and developmental delays of silkworm larvae [51].

Lipases are involved in lipid digestion and degrade dietary lipids to generate typical end products, such as free fatty acids, glycerols, partial acylglycerols, and phospholipid derivatives, in a process called lipolysis [10]. Lipases are active inside the midgut of silkworm larvae [57]. In this study, seven lipase related proteins were successfully identified. BGIBMGA001507 (Pancreatic triacylglycerol lipase, PNLIP) was upregulated in DJ48/0h and DJ48/24h. All insects use lipids for energy storage in the fat body $[10,58]$. Lipids contribute to $40 \%$ of the dry weight of an insect egg and are the most important supply of energy for the developing embryo [59]. Lipids are also incorporated in the silk gland synthetic activity and are synthesized to secrete into the anterior silk gland to promote silk spinning in silkworm larvae [60].

In addition, other proteins had been successfully identified, such as BGIBMGA001415 (Polyubiquitin-A protein, Ubi3), BGIBMGA001173 (BmdsRNase), BGIBMGA000353 (beta-1,3-glucan recognition protein 4, Bm $\beta G R P 4)$, BGIBMGA012864 (Peptidoglycan recognition protein S3, BmPGRP-S3), and BGIBMGA002288 (Lipopolysaccharide binding protein, BmLBP). Ubi3 is mainly fused with ribosomal proteins [44,45]. The interaction of Ubi3 and BGIBMGA003512 (beta-glucosidase) protects beta-glucosidase from 1-deoxynojirimycin (DNJ) strong inhibitor in digestive juice, which may indicate they are all involved in the digestion process [55]. BmdsRNase is able to digest ssRNA, ssDNA, and dsDNA, and has highest activity towards dsRNA, which is involved in the innate immune response against viral invasion [61,62]. The BGIBMGA000353 (Bm $\beta$ GRP4), BGIBMGA012864 (BmPGRP-S3), and BGIBMGA002288 (BmLBP) are all innate immunity-related proteins in the silkworm [63]. BmLBP induces nodule formation and participates in clearance of bacteria by binding to gram-negative bacteria via lipopolysaccharide [64]. BGIBMGA012864 (BmPGRP-S3) plays a role in the immune response of the silkworm to B. mori cytoplasmic polyhedrosis virus (BmCPV) infection [65]. The $\beta$-1,3-glucan recognition protein ( $\beta$ GRP) family contains two functionally different proteins, one in combination with $\beta$-1,3-glucan, and the other dubbed gram-negative binding protein (GNBP) in combination with 
gram-negative bacteria or gram-positive bacteria [63]. $\beta$ GRPs (GNBPs) trigger an innate immune response by activating the prophenoloxidase cascade and the Toll receptor pathway in hemocytes [66]. Four $B m \beta G R P$ s have been identified in B. mori and $B m \beta G R P 3$ specifically recognizes a triple-helical structure of $\beta$-1,3-glucan [63,67]. Bm $\beta$ GRP1-3 lack $\beta$-1,3-glucanase activity because the active catalytic residues for $\beta$-1,3-glucanase of Bm $\beta$ GRP1-3 are replaced with other amino acids; Bm $\beta$ GRP4 has the active catalytic residues $[63,68]$. The spatial expression profile of $B m \beta G R P 4$ was highest in the midgut, much lower but detectable in the testis and ovary, and undetectable in the remaining larval body tissues, including the mainly innate immune locations, such as hemocytes and the fat body, during day three of the fifth instar larvae. Moreover, the abundance of BGIBMGA000353 (Bm $\beta$ GRP4) was increased daily from day one to day three of the fifth instar larvae in digestive juice. $\beta G R P$ has been identified in other lepidopteran insects. $\beta$ GRP is essential to gut immunity for resistance against fungal pathogen and opportunistic pathogenic gut bacteria in Locusta migratoria manilensis [69]. $\beta$ GRP-1 is purified and characterized from the midgut lumen of Helicoverpa armigera; the mRNA of $\beta G R P-1$ is predominantly expressed in the midgut and is induced by feeding gram-negative or gram-positive bacteria, and the protein is secreted into the lumen that persist there in a stable manner [70]. $\beta$ GRP-1 does indeed possess $\beta$-1,3-glucanase activity and functions catalytically in digestion and/or pathogen defense in $H$. armigera [70]. The $\beta$ GRPs persisting in larval digestive juice are related to but distinct from the previously described $\beta$ GRP/GNBP proteins primarily found in lepidopteran hemolymph, which do not possess $\beta-1,3$-glucanase activity. The tissue-specific proteins often exhibit a strong relevance to the physiological functions of the corresponding tissues. The functional characteristics of this new midgut-specific $\beta$ GRP protein suggest that lepidopteran larvae secrete an active $\beta$-1,3-glucanase into digestive juice in order to digest $\beta$-1,3-glucans released by commensal or invading bacteria and protect midgut cells from microbial invasion [70]. Bacteria and viruses, excluding fungi, can infect B. mori larvae via oral pathway. The roles of many proteins in digestive juice to resist pathogens have been investigated in silkworms. The presence of antiviral proteins, such as multiple forms of red fluorescent protein (RFPs) [17], Bmlipase-1 [22,71], dsRNase [61,62], NADPH oxidoreductase (BmNOX) [72], serine proteases (SPs), and serine protease homologs (SPHs) [16], have been previously reported. Meanwhile, RFPs, SPs, and SPHs also have antibacterial functions.

\section{Materials and Methods}

\subsection{Collection of Samples and Protein Preparation}

Larvae of B. mori strain "radiation seven" were reared on mulberry leaves at a stable temperature of $25^{\circ} \mathrm{C}$. Digestive juice of 90 larvae per group was collected from first day (immediately after ecdysis, feeding $0 \mathrm{~h}$, referred DJ0h), second day (feeding $24 \mathrm{~h}$, referred DJ24h) and third day (feeding $48 \mathrm{~h}$, referred DJ48h) of fifth instar as previously described [9]. The midgut corresponding to the same time-point of the three stages was also collected to verify gene expression analysis. Then, each sample of digestive juice was filtered through a $0.22-\mu \mathrm{m}$ filter and quantitated by the Bradford assay kit [73]. A quantity of $20 \mu \mathrm{g}$ of each protein sample was separated by SDS-polyacrylamide gel electrophoresis (SDS-PAGE).

\subsection{Protein Digestion and iTRAQ Labeling}

Protein digestion was carried out according to previous protocols as described [74,75]. Finally, the protein suspension was digested with $40 \mu \mathrm{L}$ of trypsin buffer containing $3 \mu \mathrm{g}$ trypsin (Promega, Madison, WI, USA) at $37^{\circ} \mathrm{C}$ for $16-18 \mathrm{~h}$. Filtrate was collected and peptides were quantitated at $\mathrm{OD}_{280}$ [74]. Subsequently, the digested peptides were labeled with iTRAQ reagents following the manufacturer's instructions (Applied Biosystems, Framingham, MA, USA) using 114-tag, 115-tag, and 116-tag for feeding 0, 24 and $48 \mathrm{~h}$ samples (named Dj0h, Dj24h and Dj48h), respectively. 


\subsection{Strong Cation Exchange Fractionation and NanoLC-MS/MS Analysis}

Strong cation exchange (SCX) chromatography of the mixed samples and nanoLC-MS/MS analysis were performed as previously described $[9,75]$. Separated samples were analyzed with a $Q$ Exactive (Thermo Fisher Scientific, Waltham, MA, USA) that was coupled to an Easy nLC 1200 system (Thermo Fisher Scientific, Waltham, MA, USA) for $120 \mathrm{~min}$ to identify peptides. Detection mode was positive ion, mother ion scanning range of $300-1800 \mathrm{~m} / \mathrm{z}$. One-level mass spectrometry resolution was 70,000 at $\mathrm{m} / \mathrm{z}$ 200. The automatic gain control (AGC) target was set to $3 \mathrm{e} 6$, and maximum inject time (IT) to $10 \mathrm{~ms}$. The number of scan ranges was 1 . Dynamic exclusion duration was $30.0 \mathrm{~s}$. Mass-charge ratios of peptides and peptide fragments were collected by the following methods. Ten fragment maps were collected after each full scan. The resolution for HCD spectra was set to 17,500 at 200 $\mathrm{m} / \mathrm{z}$, and an isolation width of $2 \mathrm{~m} / \mathrm{z}$. Normalized collision energy was $30 \mathrm{eV}$. The under fill ratio was defined as $0.1 \%$. The instrument was operated under the condition that the peptide recognition mode was allowed.

\subsection{Protein Identification and Annotation}

The protein identifications were performed using Proteome Discoverer 1.4 software (Thermo Fisher, Waltham, MA, USA) running Mascot 2.2 (Matrix Science, London, UK) by searching against the silkworm database (http://www.silkdb.org/silkdb/doc/download.html) and UniProt database of the silkworm, Bombyx mori. Database search parameters were peptide mass tolerance: $20 \mathrm{ppm}$; fragment mass tolerance: $0.1 \mathrm{Da}$; enzyme: trypsin; max missed cleavages: 2; protein and peptide FDR $\leq$ 0.01 [76]. A minimum of 1 unique peptide was used for the confident protein identification. For protein quantization, a protein must contain at least two unique peptides. The quantitative protein ratios were weighed and normalized by dividing via the average value of all peptides identified. The threshold for up/downregulation of fold change of $\geq 2.0$ or $\leq 0.5$ was used to consider statistically significant differences in abundance. After obtaining the differentially expressed proteins (DEPs), protein-protein interaction network analysis was defined with STRING software (http://string-db.org/) [77], and functional annotation was performed using the gene ontology (GO) assignments $[78,79]$ and Kyoto Encyclopedia of Genes and Genomes (KEGG) pathway enrichments [80].

\subsection{Tissue Expression Patterns Based on Microarray Data}

In order to analyze tissue expression patterns of genes encoding the identified proteins, the microarray data were downloaded from the SilkMDB [2]. The microarray data of the DEP genes are provided in Table S7. The microarray data are raw. The mean value of the microarray data of genes expressed specifically in the midgut is provided in Table S9. GeneCluster 2.0 software was used to visualize the expression levels [81]. The expressed genes are defined as previously described [82].

\subsection{RT-qPCR Analysis}

The genes selected according to protein expression detected by iTRAQ were compared by reverse transcription-quantitative PCR (RT-qPCR) at the transcriptional level. Total RNA from the midgut samples of the three stages (named $\mathrm{MgOh}, \mathrm{Mg} 24 \mathrm{~h}$ and $\mathrm{Mg} 48 \mathrm{~h}$ ) was used to synthesize the first strand cDNA using the PrimeScript Reverse Transcriptase kit (TaKaRa, Dalian, China) according to the instructions of the manufacturer. RT-qPCR was performed as we previously described [83]. The information of the selected differentially expressed genes and B. mori ribosomal protein gene BmRPL3 primers are presented in Table S10.

\section{Conclusions}

The silkworm, Bombyx mori, is a complete metamorphosis insect. The nutrients needed for the vital activities of the egg, pupal, and adult stages, and proteins formed in the cocoon, are all derived from the larval stages. The silkworm feeds and grows quickly during larval stages. In particular, 
the amount of leaf ingested and digested most quickly increases from ecdysis to gluttonous stages in the fifth instar period. In this study, we used the iTRAQ proteomic technique to identify and analyze silkworm larval digestive juice proteins in this period. A total of 227 proteins were successfully identified. Among the 227 proteins, the isoelectric points of 70 proteins were between 7.01 and 11.94; 30 genes of the identified proteins were of tissue-specific expression in the midgut. The number of differentially expressed proteins (DEPs) increased with the feeding time, as found via comparing them in chronological order. Temporal proteomic analysis of digestive juice revealed developmental dynamic features related to molecular mechanisms of the principal functions of digesting, resisting pathogens, and overruling the inhibitory effects of mulberry leaves protease inhibitors (PIs) with a dynamic strategy. To our knowledge, this study is the first report on the identification of possible proteins in silkworm larval digestive juice from the ecdysis to gluttonous stages in the fifth instar period. Our findings expand the current knowledge of the complex biological processes in nutrient digestion and provide a new perspective on the developmental dynamic features related to molecular mechanisms of digestive juice in silkworm fifth instar larvae.

Supplementary Materials: Supplementary materials can be found at http:/www.mdpi.com/1422-0067/20/24/ 6113/s1. Figure S1: Expression analysis of five serine protease genes associated with immune response during infections. The silkworm strain Dazao was reared on artificial diet at a stable temperature of $25^{\circ} \mathrm{C}$. The larvae stopped feeding to get starvation on day 3 of the fifth instar for the infection experiments. Escherichia coli and Bacillus bombyseptieus were concentrated from an overnight culture in LB medium, respectively. About $200 \mu \mathrm{L}$ bacterium cells $\left(\mathrm{OD}_{600} \approx 100\right)$ were thoroughly mixed with food for each silkworm oral infection for $3 \mathrm{~h}$ and then raised at $25{ }^{\circ} \mathrm{C}$ with approximately $70 \%$ humidity. After that, time calculation was started. Fat body of silkworm larvae was collected at $24 \mathrm{~h}$ after infection for reverse transcription-quantitative PCR (RT-qPCR) analysis. The information of the five genes and B. mori ribosomal protein gene BmRPL3 primers are presented in Table S8. For each gene, the mRNA level in control is set as 1 . The experiments were repeated three times. B. mori ribosomal protein gene $B m R P L 3$ is used as an internal control. The data are the means $\pm \mathrm{SD}$ of three independent experiments. The significant differences are indicated by ${ }^{*}(p<0.05)$ or ${ }^{* *}(p<0.01)$. Figure S2: Ubi3 interacting with multiple ribosomal proteins in the STRING database. BGIBMGA001415 encodes polyubiquitin-A protein (Ubi3) that is consistent with H9IVY4. Figure S3: Multiple tissues expression profile of genes of the identified digestive juice proteins in larvae on day three of the silkworm fifth instar. Table S1: Total proteins quantified from iTRAQ experiment. Table S2: List of the proteins downregulated in silkworm digestive juice at $24 \mathrm{~h}$ and 48 h growth stages. Table S3: Gene ontology (GO) enrichment analysis of DEPs from DJ24h compared with DJ0h. Table S4: Gene ontology (GO) enrichment analysis of DEPs from DJ48h compared with DJ0h. Table S5: KEGG analysis of DEPs from DJ24h compared with DJ0h. Table S6: KEGG analysis of DEPs from DJ48h compared with DJ0h. Table S7: Microarray data of DEPs genes in larvae on day 3 of the silkworm fifth instar. Table S8: The mean value of the microarray data of genes expressed specifically in the midgut in larvae on day 3 of the silkworm fifth instar. Table S9: The mean value of the microarray data of genes expressed significant high in the midgut in larvae on day 3 of the silkworm fifth instar. Table S10: Primers of genes for RT-qPCR.

Author Contributions: P.X. performed the experiment and wrote the manuscript; M.Z. performed the literature review and analyzed the data; P.Q. collected the data; J.L. and X.W. prepared the illustrations; Y.W. suggested important research points. All authors have read and approved the final version of the manuscript.

Acknowledgments: This research was financially supported by the Jiangsu Provincial Natural Science Foundation of China (grant no. BK2012273), the National Natural Science Foundation of China (grant no. 31302035) and Key Research and Development Program (Social Development) of Zhenjiang City (grant no. SH2018001).

Conflicts of Interest: The authors declare that they have no conflicts of interest related to this publication.

\section{References}

1. Goldsmith, M.R.; Shimada, T.; Abe, H. The genetics and genomics of the silkworm, Bombyx Mori. Annu. Rev. Entomol. 2005, 50, 71-100. [CrossRef] [PubMed]

2. Xia, Q.; Cheng, D.; Duan, J.; Wang, G.; Cheng, T.; Zha, X.; Liu, C.; Zhao, P.; Dai, F.; Zhang, Z.; et al. Microarray-based gene expression profiles in multiple tissues of the domesticated silkworm, Bombyx Mori. Genome Biol. 2007, 8, R162. [CrossRef] [PubMed]

3. Kurahashi, H.; Atiwetin, P.; Nagaoka, S.; Miyata, S.; Kitajima, S.; Sugimura, Y. Absorption of mulberry root urease to the hemolymph of the silkworm, Bombyx mori. J. Insect Physiol. 2005, 51, 1055-1061. [CrossRef] [PubMed] 
4. Wu, S.; Zhang, X.; He, Y.; Shuai, J.; Chen, X.; Ling, E. Expression of antimicrobial peptide genes in Bombyx mori gut modulated by oral bacterial infection and development. Dev. Comp. Immunol. 2010, 34, 1191-1198. [CrossRef]

5. Kataoka, N.; Miyake, S.; Azuma, M. Aquaporin and aquaglyceroporin in silkworms, differently expressed in the hindgut and midgut of Bombyx mori. Insect Mol. Biol. 2009, 18, 303-314. [CrossRef]

6. Shao, Q.M.; Yang, B.; Xu, Q.Y.; Li, X.Q.; Lu, Z.Q.; Wang, C.S.; Huang, Y.P.; Soderhall, K.; Ling, E.J. Hindgut Innate Immunity and Regulation of Fecal Microbiota through Melanization in Insects. J. Biol. Chem. 2012, 287, 14270-14279. [CrossRef]

7. Baggio, M.P.; Vessaro-Silva, S.A.; Ribeiro, L.F.; Brancalhao, R.M. Morphology of the Pylorus of Bombyx mori (Linnaeus) (Lepidoptera: Bombycidae). Neotrop. Entomol. 2014, 43, 344-349. [CrossRef]

8. Vallet-Gely, I.; Lemaitre, B.; Boccard, F. Bacterial strategies to overcome insect defences. Nat. Rev. Microbiol. 2008, 6, 302-313. [CrossRef]

9. Hu, X.; Zhu, M.; Wang, S.; Zhu, L.; Xue, R.; Cao, G.; Gong, C. Proteomics analysis of digestive juice from silkworm during Bombyx mori nucleopolyhedrovirus infection. Proteomics 2015, 15, 2691-2700. [CrossRef]

10. Holtof, M.; Lenaerts, C.; Cullen, D.; Vanden Broeck, J. Extracellular nutrient digestion and absorption in the insect gut. Cell Tissue Res. 2019, 377, 397-414. [CrossRef]

11. Wang, D.D.; Dong, Z.M.; Zhang, Y.; Guo, K.Y.; Guo, P.C.; Zhao, P.; Xia, Q.Y. Proteomics Provides Insight into the Interaction between Mulberry and Silkworm. J. Proteome Res. 2017, 16, 2472-2480. [CrossRef] [PubMed]

12. Chatterjee, S.N.; Datta, R.K. Hierarchical clustering of 54 races and strains of the mulberry silkworm, Bombyx mori L.: Significance of biochemical parameters. Theor. Appl. Genet. 1992, 85, 394-402. [CrossRef] [PubMed]

13. Chatterjee, S.N.; Rao, C.G.; Chatterjee, G.K.; Ashwath, S.K.; Patnaik, A.K. Correlation between yield and biochemical parameters in the mulberry silkworm, Bombyx mori L. Theor. Appl. Genet. 1993, 87, 385-391. [CrossRef] [PubMed]

14. Chattopadhyay, G.K.; Sengupta, A.K.; Verma, A.K.; Sen, S.K.; Saratchandra, B. Esterase isozyme polymorphism, specific and nonspecific esterase, syngenic lines development and natural occurrence of a thermostable esterase in the tropical silkworm Bombyx mori L. Insect Biochem. Mol. Biol. 2001, 31, 1191-1199. [CrossRef]

15. Srinivasan, A.; Giri, A.P.; Gupta, V.S. Structural and functional diversities in lepidopteran serine proteases. Cell Mol. Biol. Lett. 2006, 11, 132-154. [CrossRef]

16. Ponnuvel, K.M.; Nithya, K.; Sirigineedi, S.; Awasthi, A.K.; Yamakawa, M. In vitro antiviral activity of an alkaline trypsin from the digestive juice of Bombyx mori larvae against nucleopolyhedrovirus. Arch. Insect Biochem. Physiol. 2012, 81, 90-104. [CrossRef]

17. Manjunatha, G.K.S.; Peter, A.; Naika, M.B.N.; Niranjana, P.; Shamprasad, P. Identification of In-Vitro Red Fluorescent Protein with Antipathogenic Activity from the Midgut of the Silkworm (Bombyx Mori L.). Protein Pept. Lett. 2018, 25, 302-313. [CrossRef]

18. Sunagar, S.G.; Lakkappan, V.J.; Ingalhalli, S.S.; Savanurmath, C.J.; Hinchigeri, S.B. Characterization of the photochromic pigments in red fluorescent proteins purified from the gut juice of the silkworm Bombyx mori L. Photochem. Photobiol. 2008, 84, 1440-1444. [CrossRef]

19. Matti, K.M.; Singh, S.S.; Savanurmath, C.J.; Hinchigeri, S.B. A unique red fluorescent protein of silkworm bearing two photochromic moieties. Photochem. Photobiol. Sci. 2009, 8, 1364-1372. [CrossRef]

20. Matti, K.M.; Savanurmath, C.J.; Hinchigeri, S.B. A promising broad spectrum antimicrobial red fluorescent protein present in silkworm excreta. Biol. Pharm. Bull. 2010, 33, 1143-1147. [CrossRef]

21. Sunagar, S.G.; Savanurmath, C.J.; Hinchigeri, S.B. The profiles of red fluorescent proteins with antinucleopolyhedrovirus activity in races of the silkworm Bombyx mori. J. Insect Physiol. 2011, 57, 1707-1714. [CrossRef] [PubMed]

22. Ponnuvel, K.M.; Nakazawa, H.; Furukawa, S.; Asaoka, A.; Ishibashi, J.; Tanaka, H.; Yamakawa, M. A lipase isolated from the silkworm Bombyx mori shows antiviral activity against nucleopolyhedrovirus. J. Virol. 2003, 77, 10725-10729. [CrossRef] [PubMed]

23. Nakazawa, H.; Tsuneishi, E.; Ponnuvel, K.M.; Furukawa, S.; Asaoka, A.; Tanaka, H.; Ishibashi, J.; Yamakawa, M. Antiviral activity of a serine protease from the digestive juice of Bombyx mori larvae against nucleopolyhedrovirus. Virology 2004, 321, 154-162. [CrossRef] [PubMed]

24. Wickham, S.; West, M.B.; Cook, P.F.; Hanigan, M.H. Gamma-glutamyl compounds: Substrate specificity of gamma-glutamyl transpeptidase enzymes. Anal. Biochem. 2011, 414, 208-214. [CrossRef] [PubMed] 
25. Gorelik, A.; Liu, F.Y.; Illes, K.; Nagar, B. Crystal structure of the human alkaline sphingomyelinase provides insights into substrate recognition. J. Biol. Chem. 2017, 292, 7087-7094. [CrossRef] [PubMed]

26. Gorelik, A.; Heinz, L.X.; Illes, K.; Superti-Furga, G.; Nagar, B. Crystal Structure of the Acid Sphingomyelinase-like Phosphodiesterase SMPDL3B Provides Insights into Determinants of Substrate Specificity. J. Biol. Chem. 2016, 291, 24054-24064. [CrossRef]

27. Whitcomb, D.C.; Lowe, M.E. Human pancreatic digestive enzymes. Dig. Dis. Sci. 2007, 52, 1-17. [CrossRef]

28. Raghavendra, R.; Neelagund, S.; Kuluvar, G.; Bhanuprakash, V.; Revanaiah, Y. Protective effect of partially purified $35 \mathrm{kDa}$ protein from silk worm (Bombyx mori) fecal matter against carbon tetrachloride induced hepatotoxicity and in vitro anti-viral properties. Pharm. Biol. 2010, 48, 1426-1431. [CrossRef]

29. Lee, T.V.; Ding, T.; Chen, Z.; Rajendran, V.; Scherr, H.; Lackey, M.; Bolduc, C.; Bergmann, A. The E1 ubiquitin-activating enzyme Uba1 in Drosophila controls apoptosis autonomously and tissue growth non-autonomously. Development 2008, 135, 43-52. [CrossRef]

30. Fujii, T.; Banno, Y. Identification of a novel function of the silkworm integument in nitrogen metabolism: Uric acid is synthesized within the epidermal cells in B. mori. Insect Biochem. Mol. Biol. 2019, 105, 43-50. [CrossRef]

31. Ozawa, R.; Matsumoto, S. Intracellular signal transduction of PBAN action in the silkworm, Bombyx mori: Involvement of acyl CoA reductase. Insect Biochem. Mol. Biol. 1996, 26, 259-265. [CrossRef]

32. Yamamoto, K.; Wilson, D.K. Identification, characterization, and crystal structure of an aldo-keto reductase (AKR2E4) from the silkworm Bombyx mori. Arch. Biochem. Biophys. 2013, 538, 156-163. [CrossRef] [PubMed]

33. Kanaya, T.; Kobayashi, J. Purification and characterization of an insect haemolymph protein promoting in vitro replication of the Bombyx mori nucleopolyhedrovirus. J. Gen. Virol. 2000, 81, 1135-1141. [CrossRef] [PubMed]

34. Iatrou, K.; Swevers, L. Transformed lepidopteran cells expressing a protein of the silkmoth fat body display enhanced susceptibility to baculovirus infection and produce high titers of budded virus in serum-free media. J. Biotechnol. 2005, 120, 237-250. [CrossRef]

35. Okada, T.; Ishiyama, S.; Sezutsu, H.; Usami, A.; Tamura, T.; Mita, K.; Fujiyama, K.; Seki, T. Molecular cloning and expression of two novel beta-N-acetylglucosaminidases from silkworm Bombyx mori. Biosci. Biotechnol. Biochem. 2007, 71, 1626-1635. [CrossRef]

36. Kimura, S. Genetics of insect hemolymph alpha-mannosidase in the silkworm, Bombyx mori. Biochem. Genet. 1983, 21, 713-724. [CrossRef]

37. Yamamoto, K.; Higashiura, A.; Suzuki, M.; Shiotsuki, T.; Sugahara, R.; Fujii, T.; Nakagawa, A. Structural characterization of an aldo-keto reductase (AKR2E5) from the silkworm Bombyx mori. Biochem. Biophys. Res. Commun. 2016, 474, 104-110. [CrossRef]

38. Uno, T.; Ueno, M.; Kikuchi, M.; Aizono, Y. Purification and characterization of nucleoside diphosphate kinase from the brain of Bombyx mori. Arch. Insect Biochem. Physiol. 2002, 50, 147-155. [CrossRef]

39. Isobe, M.; Kai, H.; Kurahashi, T.; Suwan, S.; Pitchayawasin-Thapphasaraphong, S.; Franz, T.; Tani, N.; Higashi, K.; Nishida, H. The molecular mechanism of the termination of insect diapause, part 1: A timer protein, TIME-EA4, in the diapause eggs of the silkworm Bombyx mori is a metallo-glycoprotein. Chembiochem A Eur. J. Chem. Biol. 2006, 7, 1590-1598. [CrossRef]

40. Xu, L.; Liang, H.; Niu, Y.; Wang, Y.; Sima, Y.; Xu, S. Differential expression of the Bombyx mori diapause-termination timer gene Ea4 in diapause-inducing temperature and photoperiod. Arch. Insect Biochem. Physiol. 2012, 79, 182-194. [CrossRef]

41. Ngernyuang, N.; Kobayashi, I.; Promboon, A.; Ratanapo, S.; Tamura, T.; Ngernsiri, L. Cloning and expression analysis of the Bombyx mori alpha-amylase gene (Amy) from the indigenous Thai silkworm strain, Nanglai. J. Insect Sci. 2011, 11, 38. [CrossRef] [PubMed]

42. Mitsumasu, K.; Azuma, M.; Niimi, T.; Yamashita, O.; Yaginuma, T. Membrane-penetrating trehalase from silkworm Bombyx mori. Molecular cloning and localization in larval midgut. Insect Mol. Biol. 2005, 14, 501-508. [CrossRef] [PubMed]

43. Lin, P.; Cheng, T.; Jin, S.; Jiang, L.; Wang, C.; Xia, Q. Structural, evolutionary and functional analysis of APN genes in the Lepidoptera Bombyx mori. Gene 2014, 535, 303-311. [CrossRef] [PubMed]

44. Archibald, J.M.; Teh, E.M.; Keeling, P.J. Novel ubiquitin fusion proteins: Ribosomal protein P1 and actin. J. Mol. Biol. 2003, 328, 771-778. [CrossRef] 
45. Catic, A.; Ploegh, H.L. Ubiquitin-Conserved protein or selfish gene? Trends Biochem. Sci. 2005, 30, 600-604. [CrossRef]

46. Zhou, L.; Li, H.; Hao, F.; Li, N.; Liu, X.; Wang, G.; Wang, Y.; Tang, H. Developmental Changes for the Hemolymph Metabolome of Silkworm (Bombyx mori L.). J. Proteome Res. 2015, 14, 2331-2347. [CrossRef]

47. Grzelak, K. Control of expression of silk protein genes. Comp. Biochem. Physiol. Part B Biochem. Mol. Biol. 1995, 110, 671-681. [CrossRef]

48. Hou, Y.; Zou, Y.; Wang, F.; Gong, J.; Zhong, X.; Xia, Q.; Zhao, P. Comparative analysis of proteome maps of silkworm hemolymph during different developmental stages. Proteome Sci. 2010, 8, 45. [CrossRef]

49. Ye, J.; Li, Y.; Liu, H.W.; Li, J.; Dong, Z.; Xia, Q.; Zhao, P. Genome-Wide Identification and Characterization of Carboxypeptidase Genes in Silkworm (Bombyx mori). Int. J. Mol. Sci. 2016, 17, 1203. [CrossRef]

50. Konno, K.; Ono, H.; Nakamura, M.; Tateishi, K.; Hirayama, C.; Tamura, Y.; Hattori, M.; Koyama, A.; Kohno, K. Mulberry latex rich in antidiabetic sugar-mimic alkaloids forces dieting on caterpillars. Proc. Natl. Acad. Sci. USA 2006, 103, 1337-1341. [CrossRef]

51. Gan, Q.; Zhang, X.W.; Zhang, D.B.; Shi, L.; Zhou, Y.; Sun, T.T.; Jiang, S.; Gao, J.S.; Meng, Y. BmSUC1 is essential for glycometabolism modulation in the silkworm, Bombyx mori. Biochim. Biophys. Acta Gene Regul. Mech. 2018, 1861, 543-553. [CrossRef] [PubMed]

52. Mehrabadi, M.; Bandani, A.R.; Mehrabadi, R.; Alizadeh, H. Inhibitory activity of proteinaceous alpha-amylase inhibitors from Triticale seeds against Eurygaster integriceps salivary alpha-amylases: Interaction of the inhibitors and the insect digestive enzymes. Pestic. Biochem. Physiol. 2012, 102, 220-228. [CrossRef]

53. Da Lage, J.L. The Amylases of Insects. Int. J. Insect Sci. 2018, 10, 1179543318804783. [CrossRef] [PubMed]

54. Asano, N.; Yamashita, T.; Yasuda, K.; Ikeda, K.; Kizu, H.; Kameda, Y.; Kato, A.; Nash, R.J.; Lee, H.S.; Ryu, K.S. Polyhydroxylated alkaloids isolated from mulberry trees (Morusalba L.) and silkworms (Bombyx mori L.). J. Agric. Food Chem. 2001, 49, 4208-4213. [CrossRef]

55. Li, X.T.; Shi, L.G.; Dai, X.P.; Chen, Y.J.; Xie, H.Q.; Feng, M.; Chen, Y.Y.; Wang, H.B. Expression plasticity and evolutionary changes extensively shape the sugar-mimic alkaloid adaptation of nondigestive glucosidase in lepidopteran mulberry-specialist insects. Mol. Ecol. 2018, 27, 2858-2870. [CrossRef]

56. Daimon, T.; Taguchi, T.; Meng, Y.; Katsuma, S.; Mita, K.; Shimada, T. Beta-fructofuranosidase genes of the silkworm, Bombyx mori: Insights into enzymatic adaptation of B. mori to toxic alkaloids in mulberry latex. J. Biol. Chem. 2008, 283, 15271-15279. [CrossRef]

57. Horne, I.; Haritos, V.S.; Oakeshott, J.G. Comparative and functional genomics of lipases in holometabolous insects. Insect Biochem. Mol. Biol. 2009, 39, 547-567. [CrossRef]

58. Van der Horst, D.J. Insect adipokinetic hormones: Release and integration of flight energy metabolism. Comp. Biochem. Physiol. Part B Biochem. Mol. Biol. 2003, 136, 217-226. [CrossRef]

59. Fruttero, L.L.; Leyria, J.; Canavoso, L.E. Lipids in Insect Oocytes: From the Storage Pathways to Their Multiple Functions. Results Probl. Cell Differ. 2017, 63, 403-434. [CrossRef]

60. Wang, X.; Li, Y.; Liu, Q.; Tan, X.; Xie, X.; Xia, Q.; Zhao, P. GC/MS-based metabolomics analysis reveals active fatty acids biosynthesis in the Filippi's gland of the silkworm, Bombyx mori, during silk spinning. Insect Biochem. Mol. Biol. 2019, 105, 1-9. [CrossRef]

61. Arimatsu, Y.; Kotani, E.; Sugimura, Y.; Furusawa, T. Molecular characterization of a cDNA encoding extracellular dsRNase and its expression in the silkworm, Bombyx mori. Insect Biochem. Mol. Biol. 2007, 37, 176-183. [CrossRef] [PubMed]

62. Liu, J.H.; Swevers, L.; Iatrou, K.; Huvenne, H.; Smagghe, G. Bombyx mori DNA/RNA non-specific nuclease: Expression of isoforms in insect culture cells, subcellular localization and functional assays. J. Insect Physiol. 2012, 58, 1166-1176. [CrossRef] [PubMed]

63. Tanaka, H.; Ishibashi, J.; Fujita, K.; Nakajima, Y.; Sagisaka, A.; Tomimoto, K.; Suzuki, N.; Yoshiyama, M.; Kaneko, Y.; Iwasaki, T.; et al. A genome-wide analysis of genes and gene families involved in innate immunity of Bombyx mori. Insect Biochem. Mol. Biol. 2008, 38, 1087-1110. [CrossRef] [PubMed]

64. Koizumi, N.; Imamura, M.; Kadotani, T.; Yaoi, K.; Iwahana, H.; Sato, R. The lipopolysaccharide-binding protein participating in hemocyte nodule formation in the silkworm Bombyx mori is a novel member of the C-type lectin superfamily with two different tandem carbohydrate-recognition domains. FEBS Lett. 1999, 443, 139-143. [CrossRef]

65. Gao, K.; Deng, X.Y.; Qian, H.Y.; Qin, G.X.; Hou, C.X.; Guo, X.J. Cloning and expression analysis of a peptidoglycan recognition protein in silkworm related to virus infection. Gene 2014, 552, 24-31. [CrossRef] 
66. Ao, J.Q.; Ling, E.; Yu, X.Q. A Toll receptor from Manduca sexta is in response to Escherichia coli infection. Mol. Immunol. 2008, 45, 543-552. [CrossRef]

67. Takahasi, K.; Ochiai, M.; Horiuchi, M.; Kumeta, H.; Ogura, K.; Ashida, M.; Inagaki, F. Solution structure of the silkworm betaGRP/GNBP3 N-terminal domain reveals the mechanism for beta-1,3-glucan-specific recognition. Proc. Natl. Acad. Sci. USA 2009, 106, 11679-11684. [CrossRef]

68. Zou, Z.; Evans, J.D.; Lu, Z.; Zhao, P.; Williams, M.; Sumathipala, N.; Hetru, C.; Hultmark, D.; Jiang, H. Comparative genomic analysis of the Tribolium immune system. Genome Biol. 2007, 8, R177. [CrossRef]

69. Zheng, X.; Xia, Y. beta-1, 3-Glucan recognition protein (betaGRP) is essential for resistance against fungal pathogen and opportunistic pathogenic gut bacteria in Locusta migratoria manilensis. Dev. Comp. Immunol. 2012, 36, 602-609. [CrossRef]

70. Pauchet, Y.; Freitak, D.; Heidel-Fischer, H.M.; Heckel, D.G.; Vogel, H. Immunity or digestion: Glucanase activity in a glucan-binding protein family from Lepidoptera. J. Biol. Chem. 2009, 284, 2214-2224. [CrossRef]

71. Jiang, L.; Zhao, P.; Cheng, T.C.; Sun, Q.; Peng, Z.W.; Dang, Y.H.; Wu, X.W.; Wang, G.H.; Jin, S.K.; Lin, P.; et al. A transgenic animal with antiviral properties that might inhibit multiple stages of infection. Antivir. Res. 2013, 98, 171-173. [CrossRef] [PubMed]

72. Selot, R.; Kumar, V.; Sekhar, S.C.; Kumar, P.G. Molecular characterization and expression analysis of BmNOX in two strains of Bombyx mori with contrasting viral resistance phenotype. Arch. Insect Biochem. Physiol. 2010, 73, 163-175. [CrossRef] [PubMed]

73. Bradford, M.M. A rapid and sensitive method for the quantitation of microgram quantities of protein utilizing the principle of protein-dye binding. Anal. Biochem. 1976, 72, 248-254. [CrossRef]

74. Wisniewski, J.R.; Zougman, A.; Nagaraj, N.; Mann, M. Universal sample preparation method for proteome analysis. Nat. Methods 2009, 6, 359-362. [CrossRef]

75. Yu, H.; Wang, X.; Xu, J.; Ma, Y.; Zhang, S.; Yu, D.; Fei, D.; Muhammad, A. iTRAQ-based quantitative proteomics analysis of molecular mechanisms associated with Bombyx mori (Lepidoptera) larval midgut response to BmNPV in susceptible and near-isogenic strains. J. Proteom. 2017, 165, 35-50. [CrossRef]

76. Sandberg, A.; Lindell, G.; Kallstrom, B.N.; Branca, R.M.; Danielsson, K.G.; Dahlberg, M.; Larson, B.; Forshed, J.; Lehtio, J. Tumor proteomics by multivariate analysis on individual pathway data for characterization of vulvar cancer phenotypes. Mol. Cell Proteom. 2012, 11, M112-016998. [CrossRef]

77. Szklarczyk, D.; Gable, A.L.; Lyon, D.; Junge, A.; Wyder, S.; Huerta-Cepas, J.; Simonovic, M.; Doncheva, N.T.; Morris, J.H.; Bork, P.; et al. STRING v11: Protein-protein association networks with increased coverage, supporting functional discovery in genome-wide experimental datasets. Nucleic Acids Res. 2019, 47, D607-D613. [CrossRef]

78. Quevillon, E.; Silventoinen, V.; Pillai, S.; Harte, N.; Mulder, N.; Apweiler, R.; Lopez, R. InterProScan: Protein domains identifier. Nucleic Acids Res. 2005, 33, W116-W120. [CrossRef]

79. Gotz, S.; Garcia-Gomez, J.M.; Terol, J.; Williams, T.D.; Nagaraj, S.H.; Nueda, M.J.; Robles, M.; Talon, M.; Dopazo, J.; Conesa, A. High-throughput functional annotation and data mining with the Blast2GO suite. Nucleic Acids Res. 2008, 36, 3420-3435. [CrossRef]

80. Kanehisa, M.; Goto, S.; Sato, Y.; Furumichi, M.; Tanabe, M. KEGG for integration and interpretation of large-scale molecular data sets. Nucleic Acids Res. 2012, 40, D109-D114. [CrossRef]

81. Golub, T.R.; Slonim, D.K.; Tamayo, P.; Huard, C.; Gaasenbeek, M.; Mesirov, J.P.; Coller, H.; Loh, M.L.; Downing, J.R.; Caligiuri, M.A.; et al. Molecular classification of cancer: Class discovery and class prediction by gene expression monitoring. Science 1999, 286, 531-537. [CrossRef] [PubMed]

82. Zhao, P.; Wang, G.H.; Dong, Z.M.; Duan, J.; Xu, P.Z.; Cheng, T.C.; Xiang, Z.H.; Xia, Q.Y. Genome-wide identification and expression analysis of serine proteases and homologs in the silkworm Bombyx mori. BMC Genom. 2010, 11, 405. [CrossRef] [PubMed]

83. Zhang, M.R.; Qin, S.; Xu, P.Z.; Zhang, G.Z. Identifying potential maternal genes of Bombyx mori using digital gene expression profiling. PLoS ONE 2018, 13, e0192745. [CrossRef] [PubMed]

(C) 2019 by the authors. Licensee MDPI, Basel, Switzerland. This article is an open access article distributed under the terms and conditions of the Creative Commons Attribution (CC BY) license (http://creativecommons.org/licenses/by/4.0/). 